\title{
Evaluating the Survival Strategies Adopted by Single Mothers to Enhance their Livelihood in Zimbabwe from a Literature Review Lenses
}

\author{
S. M. Kang'ethe \\ Mafa Itai \\ University of Fort Hare, Department of Social Work and Social Development, Private bag X1314 ALICE. 5700, South Africa \\ Email: <skangethe@ufh.ac.za>, <200909691@ufh.ac.za>
}

\section{Doi:10.5901/mjss.2014.v5n27p1222}

\section{Abstract}

Poverty and its eradication are presently at the pinnacle of all global development policies inexorably attracting the attention of numerous prominent organizations including the World Bank and the United Nations. However and irrefutably, feminization of poverty especially among the single mothers is a huge stumbling block to making a significant score to the Millennium Development Goal (MDGs) number three, which is concerned with women empowerment. The aim of this article is, through a review of literature methodology, to explore the survival strategies adopted by single mothers. Findings indicate the following factors underpinning the prevalence of single mothers in Zimbabwe: divorce and separation; death from diseases such as HIV/AIDS; out-of-wedlock births; and choice of being single mothers. Single mothers were also found to enjoy support from the following sources: international/donor organization, government, family and communities; and from faith based organizations. Ultimately, the paper reveals the following survival strategies: prostitution, entrepreneurship and engagement in women group organizations. As the way forward, the paper recommends the following: re-implementing balanced and favourable women friendly policies; erecting educational and sustainable projects friendly to women; and fostering partnership between the government and the NGOs dealing with women development and advancement.

Keywords: Evaluation; Survival Strategies; Single Mothers; Feminization of Poverty, Feminization of HIVIAIDS

\section{Problem Statement}

Certainly, modernization and westernization have brought major alterations in parenting styles, the family structures and the composition of the family itself. Consequently, many fathers are either physically unavailable or are not fulfilling their paternal responsibilities in raising children. Therefore, this structural development brings with it problems such as poverty, placing the duty of raising children solely in the hands of their mothers. Without any doubt, the economic, social, educational, moral and emotional functioning of these children is compromised because these mothers are overwhelmed with providing the crucial needs of the children in an economically hostile nation like Zimbabwe. They have to dynamically make ends meet to ensure the enhancement of their children's wellbeing with or without support from the father. To this end, feminization of poverty and child poverty has been documented to be infuriating day-in-day out. Therefore, these researchers consider it pertinent and fundamental to evaluate and explore the effectiveness of the survival strategies implemented by single mothers. These researchers hope to unearth mechanisms that could ameliorate the daunting circumstances surrounding single motherhood in developing nations.

\section{Introduction and Background}

Globally, the trend on single motherhood has taken a geometric increase curve. A change in the family structure from the conventional pattern of two parents to a single one has been identified (Landau and Griffiths, 2007). This is attributable to the anticipated effects of modernization, civilization and globalization as the world has evolved into a global village sharing information, values and culture (Kang'ethe, 2014a). Cultural erosion in Africa and an espousal of a western lifestyle have corroded the ligament that distinguished Africans from the non-Africans. Landau and Griffiths' findings are also supported by Dlamini (2006) who reveal the following unsettling statistics of children living with their mothers: South Africa (34.4\%), Namibia (27.3\%) and Zimbabwe (26.3\%).

The above figures may aid to elucidate the feminization of poverty phenomenon and child poverty as these are the groups most vulnerable to poverty and low standards of living. No wonder, poverty and its eradication have claimed the 
full attention of all global development policies, especially the Millennium Development Goals (MDGs) number one, two and three (Gebre-Egziabher, 2010). It also divulges why poverty has been declared a state of emergence in many countries especially of the developing world, Zimbabwe being one of the worst affected (Gilbert, 2004). It goes without saying that there is therefore a dire need to check if the already implemented strategies are valid, adequate and relevant in eradicating poverty lest the already out-of-hand matter gets out of control.

Zimbabwe's economic and political hegemony can also be cited as compelling factors aggravating the state of single mothers in Zimbabwe (Alao, 2012; Palaez and Palaez, 2007). In fact the current economic recession in Zimbabwe that made headline news the world over left most families financially crippled, surviving mainly from external handouts of those generous. Daily intra-familial squabbles over food and marriage security lead to divorce, separations leaving women sole parents with the twofold tasks of child care. As a result, these circumstances have explained the phenomenon of feminization of poverty (Kang'ethe, 2013). If the state of poverty in Zimbabwe is not addressed promptly, then the phenomenon of single motherhood is going to intensify feminization of poverty that will immensely compromise the fulfilment of Millennium Development Goals whose stock taking is pegged on the year 2015 (UNDP, 2004).

\section{Methodology}

This article has adopted a literature review methodology to discuss, debate and form discourses surrounding the state of single motherhood in Zimbabwe. The article has consulted journals, books and other eclectic documents on single motherhood.

\section{Dynamics Asscociated with the Phenomenon of Single Motherhood in Zimbabwe}

\subsection{Divorce and Separation}

It seems as if the tendon that used to hold man and women together till death do them part is weakening because marriage are now more or less like convenience contracts. Alterations in marriages, an increase in the participation of women on the job market and feminists theories have all lead to a significantly high proportion of people undergoing divorce in today's life (Yarber and Sharp, 2010). Activists against women abuse have also given women a voice and thereby empowering them to escape from abusive marriages. There has been a conflict of understanding between the imperatives of human rights associated with both female and male genders. Apparently, traditional and patriarchal ways of life condoned many aspects of gender based violence (The World Bank, 2003). Migration has also greatly contributed to separations and divorce. Makina and Kanyeze (2010) unearth that about 3040000 Zimbabweans have migrated to other countries with South Africa being a refuge to over 2 million of them. These figures could be a little lower than the actual ones because they do not include illegal immigrants or boarder jumpers.

\subsection{Decline in patriarchy and lessened control of women by men}

In the $19^{\text {th }}$ century, when patriarchal influence was still unchallenged, women were dependant on their fathers and this made living in a male-headed family household the most desirable option. In the $20^{\text {th }}$ century however, more women are increasingly being employed in almost equal measures as their male counterparts. This has proverbially given them wings and the freedom to fly away in case they are taken for granted (Hein, 2005). In the study carried out by Yarber and Sharp (2010), 75\% of the people surveyed agreed that a couple was supposed to remain intertwined in marriage for the full span of it's lifetime except in the case of extreme inevitable circumstances. Although patriarchy has been blamed for causing human rights violations, these researchers think that some aspects of patriarchy need to be revisited as a panacea to reposition the erstwhile place of marriage in societies. Apparently, these researchers would opt that societies carry out a cost benefit analysis and consider the merits and demerits of diluting patriarchy. Perhaps this is why Kang'ethe (2014b), in his literature on the panacea of cultures is calling for reposition of cultural values and cultural practitioners as a way of seeking the indigenously grounded solutions to their problems. The state of divorce and separation are now stifling development and tearing apart the fibres that held family structures strong.

\subsection{Death}

Mortality is one of the leading factors causing single motherhood. Death is a drastic occurrence that leaves a gap that will never be filled. Among the deeply affected are the wives and children of the deceased. Today especially in many 
countries of the developing world, high incidence of deaths may be attributable mainly to the HIVIAIDS pandemic with Zimbabwe ranking among the most affected countries in Africa (Mahati et al, 2006). It is also interesting to note that among the leading causes of death are preventable diseases such as malaria, tuberculosis, cholera and diarrhoea (Homann, Koslowski and Luetge, 2007). Death caused by HIVIAIDS is dreadfully high prompting some researchers to remark this revealing in their study that, "All families in this community have a grave of a person who has succumbed to AIDS" (Mahati et al, 2006; 79). Where fathers/husbands are snatched out of their families by death, the wife and children cry foul as they try to sail through life's challenges.

\subsection{Out-of-wed births}

Although this is slowly but surely fading away, children out of marriage used to be a taboo in many Afican and Christian nations like Zimbabwe (Yarber and Sharp, 2010). Observably and conventionally, a sexual culture where pre marital sex is tolerated has emerged as a well accepted norm (Neckerman, 2004). According to Yarber and Sharp (2010), about two thirds of non-marital births are unplanned. "The rapid increase in the prevalence of non-marital child bearing is evidence of, and contribution to, the erosion of norms against behaviour traditionally described by such terms as 'illegitimacy" and "bastard" (Yarber and Sharp, 2010; 8). The media, peer pressure and drug use have influenced this increase because they tend to disband any personal defence. The limited contraceptive use among sexually active adolescents also contributes to the state of unplanned and unwanted pregnancies (The World Bank, 2003). This then calls for more educational information on teenage pregnancy and sexually transmitted disease such as HIVIAIDS if single motherhood is to be curbed.

\subsection{Embracing single motherhood out of choice}

Normally, single motherhood creeps in through unforeseen quandaries such as divorce, death and unplanned pregnancies. Interestingly, there are some women who liberally desire to become solo mothers. "Some women have such a strong desire for motherhood that they wonder even in their twenties why they have to wait for a husband" (Morrissette, 2008; 6). Lone motherhood is then the end product as marriage and sex are gradually but unquestionably losing their sacredness. It is that desire to enjoy the joys of motherhood; the fulfilment and incomparable satisfaction of carrying a life and caring for a child that make them take such a controversial decision despite the obvious drawbacks thereof. Apart from that, the propensity of men to embrace and uphold the norm of multiple and concurrent partners without taking their sexual responsibility and accountability could also be contributing to some women opting to take the route of being solo mothers. This is especially the case with economically stable women (The Word Bank, 2003). In Zimbabwe, for example, condemnation of this dispensation is still prevalent among many traditional and Christian families. A family in this part of the world is still viewed through religious and cultural lenses where a child has to have a bona fide father, and a accustomed norm for a woman to live with a man (Yarber and Sharp, 2010).

\section{Support Mechanisms Available to Single Mothers}

\subsection{International/Donor support}

International organisations such as the United Nations and The World Bank have joined forces in an attempt to alleviate poverty and empowering women to promote gender equality. This is in conjunction with the Development Millennium Goals to be attained by 2015 (The Economic Report of Africa, 2005). Most proverbial Non Governmental Organizations (NGOs) such as World Vision, United Nations Children's Fund, United Nations Women and other facets that empower women and children to enhance their holistic functioning stem from international bodies. As some researchers have noted "...many of these NGOs have focused principally on social protection and poverty alleviation, which has involved setting up self-help programmes and activities to assist women in the transition period" (Corcoran-Nantes, 2005; 180). It is unfortunate that the political climate in the country has negatively interfered with many aspects of foreign funding. For example the accusations of the Zimbabwe government being autocratic, undemocratic and failing to uphold the human rights of all the political players has led to the western world countries slamming economic sanctions to the country. However, it should be lost that despite that international community has not hugely dwindled their desire and interest to assist the Zimbabweans especially in issues of women empowerment. However, the bad economic climate and especially the adoption of the US Dollar led to downsizing and closure of many NGOs (Alao, 2012; Chikuhwa, 2008). 


\subsection{Government support}

To say the least, every government is bound by its constitutions to protect and take social and economic responsibility of its citizens. It is to this end that developed nations like the USA adopt an institutionalised view to welfare, shouldering the needs of her citizens for self satisfaction while developing nations like Zimbabwe only help those who are helpless and with no any other way to survive. This is adopting a residual approach (Zastrow, 2009). It is again the government's responsibility and accountability to formulate policies that foster gender equality and ensuring the safety of children and vulnerable women. However, the state of poverty that the country of Zimbabwe coupled with insufficient and ambiguous policy has not afforded single mothers to get any meaningful economic or social assistance (Couture, 2007). Instead, adverse policies such as completely and mercilessly demolishing houses built on government illegal land under the "Operation Murambatsvina" (Operation Drive Filth) has impoverished single women even more (Chikuhwa, 2008; Hein, 2005). It is these researchers" contention that the government should be a shield of the citizens rather than being the sword that claims the financial and economic freedom of many. Therefore, the government of Zimbabwe has does not make a significant score as far as turning round the lives of the single mothers is concerned. In these researchers' perspective again, the country is even scoring only paltry in the achievement and fulfilment of Millennium Development Goal number three that envisages to see women achieve economic empowerment, gender equality and equality. Its political disposition, could perhaps be the hugest stumbling block to implementing and operationalizing the gender empowerment policies, guidelines and interventions (Alao, 2012; Kanchense, 2008; Chikuhwa, 2008).

\subsection{Family and Communal support}

Irrespective of the alterations in the family structure and its composition, the family is still highly recognized as the centre of every person's existence. Yarber and Sharp (2010) applaud it as the primary agent of socialization. Often, the family and friends do come in handy in times of need for financial assistance, a shoulder to lean on and a stand-by person in times of emergencies. This is why people who separate themselves from extended family structures are viewed as unwise considering the values that such communal structures can bring to individuals (Morrissette, 2008). However, it is nonetheless sad to reveal that some family members despicably abuse children left in their care for instance when the mother goes to work. These include acts such as denying them access to food and assigning them heavy tasks (Mahati et $\mathrm{al}, 2006$ ). The gravest state of affairs indicating that family structures can be perfidious is when family members become the perpetrators of social vices such as rape, incest and molestation to children instead of proving protection, father figures and role models. Some women who find themselves in this kind of dilemma prefer to look for alternative care for their children and reject communities and communalism as support structures for their children (Bose, 2010).

\subsection{Religious support}

Christianity is pivotal to selflessness and looking out for one another (Kang'ethe \& Rhakudu, 2010). The decay and fading away of the extended family has given birth to the increased need for the religious sect to intercede and intervene, taking over the function once played by the family (Couture, 2007). Although religion such as Catholics disapprove divorce and choice of single parenthood (Yarber and Sharp, 2010), they should not, in these researchers' contention be prejudicial, but should rather continue the good work of assisting the economically and socially vulnerable such as the single mothers. Such assistance package includes food stuffs, clothing, shelter, school fees or projects that promote spiritual, mental and social sanity. Increasingly, single mothers are facing the state of feminization of poverty and therefore need a reaching hand to offer them social and economic assistance. Communities' appreciation of the rights of children to basic needs such as food shelter, emotional support should make them extend help to the single mothers (Exil, 2005). According to Johnson (2009), a greater connection with the Creator, family and supportive friends brings a new hope which eases the weighty yoke that single motherhood comes with. The church, then steps in the gap to mould God fearing men and women who are responsible, wise and empowered to face the challenges that confront them in life (Byamugisha, Steiniz, Williams \& Zondi, 2002).

\section{Survival Strategies Adopted by Single Mothers in Zimbabwe}

\subsection{Prostitution}

Although many definitions encircle the term prostitution, it is widely accepted as the buying and selling of sex (Ditmore, 
2011; Frances, 2007). Ditmore (2011) divulges that approximately 70\% of female prostitutes are single mothers struggling to support their children. From a glance, it is very easy to label these women as immoral, lazy and selfish; but sometimes it takes personal experience to make realistic judgements. In Zimbabwe, prostitution take many forms, some being pseudo prostitution in nature. This is a situation in which sexual favours may take not only financial exchange, but also various favours such as love, and taking care of some agreed favours such as buying food, paying house rent etc. Increasingly, prostitution or pseudo prostitution is taking the form of "small houses" phenomenon (Sachikonye, 2011; 175). This is where a woman has a concealed relationship with a married man (normally rich man) for a period of time without any formalization of their relationship. In the United Kingdom, certificates for prostitution are offered with government regulation (Frances, 2007). Conversely, in Zimbabwe, prostitution is an offence punishable by the law even though this does not hinder its prevalence. In fact, other prostitutes lament that police officers demand sex from those caught selling sex in exchange for their freedom (Frances, 2007). It is sad that the community is worsening the lives of single mothers by scratching them socially and labelling them instead of educating and supporting them in matters of HIV and AIDS (Hayward, 2010). Although prostitution is a morally undesirable social vice, societies need to own up the fact that the phenomenon is a structural adjustment to already destroyed social structures of social and economic sustenance. Although mitigating the effects of HIVIAIDS is a huge worry besetting many African countries, it remains an incontrovertible fact that these women need to put food on the table at the end of the day. They also have to attend to other basic needs of their children. This perspective, however, mirrors the research findings by some individuals living with HIVIAIDS in Botswana who owned up practising prostitution as an economic bolstering measure, considering and relegating the issue of HIVIAIDS prevention a second priority. They needed to feed their children and themselves through prostitution (Kang'ethe, 2012).

\subsection{Entrepreneurship}

The term entrepreneurship entails the initiation of a business for the purpose of making a profit (Elam, 2008;). Single mothers also explore this road in pursuit of financial freedom. "The pursuit of entrepreneurship as a means of maximizing capital is a strategy particularly compatible with male culture. And thus one that may be perceived as more appropriate or realistic for men compared to women, particularly mothers" (Elam, 2008; 57). So despite the economic problems of Zimbabwe (Kanchense, 2008), the once-off compensation plan offered to war veterans and the political struggles gave an opportunity for many especially men to engage in business. However, engagement in entrepreneurship remains a gendered phenomenon making it hard for women especially single mothers to keep afloat (Alao, 2012; Chikuhwa, 2008). Perhaps the biggest hurdle to venture and engage in business is people's failure to raise the collateral required by financial institutions to secure funding. This is also coupled with inadequate bookkeeping skills (Delchambre, 2010). However, some single mothers have defied the odd and myth that entrepreneurship is only an engagement of men and have been able to compete in this capitalistic and male-dominated industry. This they may achieve through sheer hard work, dedication, determination and the desire to free their children from the chains of poverty.

\subsection{Women's organizations}

People need each other in good and trying times for comfort and encouragement. "When you survive a fall, share your experience with the group so that we are constantly learning from each other" (Kanchense, 2008; 412). Although it is true that the homogeneity of one's problem does not make it vanish, it is also true that any saddle is lighter if shared among many people. Lack of a partner exacerbates the economic, emotional, psychological and spiritual well being of single mothers (Kilbride, 2012). In the same manner, these single mothers have to play a dual role of father and mother to their children. Hence forth, the women groups sometimes known as "stokvel" bring the much needed information and relief to avoid burnout and being overwhelmed. These women groups are also accredited for the initiations of sustainable and developmental projects like poultry which are driven by the desire for self reliance and women empowerment (Kanchense, 2008). Depending on the determination of the group members, destructive sects such as drug lords, human trafficking agents and brothel owners can also be birthed by such cooperatives (Ditmore, 2011). Hence the fruition of any cooperative is heavily dependent upon the degree of wilfulness of these women to emancipate themselves from the poverty trap through self reliance (boipelego in setswana; vukuzenzele in IsiXhosa; and Mushandirapamwe in Shona) (Peck, 2004). 


\section{Way Forward to Bolster the Lives of Single Mothers}

\subsection{Re-implementing balanced and favourable policies}

Male dominance has always been an issue especially in African nations. In Zimbabwe, many women rights activists have come forward to propose policies that are aimed at levelling out the oblique cultural and social circumstances (Ismael, 2006). For example in Zimbabwe, a child can not apply for a birth certificate or passport in the absence of a father, but can surely do so in the absence of the mother. Such policies undermine the importance of a mother portraying fathers as superior (Chan,t 2006). In this case, what are single mothers supposed to do to enrol their children to school? Also, the country should implement and operationalize an affirmative action that will facilitate women especially single women to secure many key positions in various important positions in the country's governance structures. This affirmative action would achieve an important milestone of diluting the prevalent dominance culture of men at work places, in politics and economic positions. The phenomenon will also aid significant role of achieving single women empowerment as well as achieve poverty reduction to a greater extent (Kanchense, 2008).

\subsection{Erecting educational and sustainable projects}

As much as there may be many projects in Zimbabwe that are aimed at alleviating poverty, it is crucial to preach the gospel of mental emancipation unto these single mothers. Empowerment starts from the mind and goes on to the hands (Zastrow, 2010). It is therefore not enough to tell them of economic freedom if their minds are still under the dominance of men (Malaba, 2006). Mental empowerment with appropriate support, then, is the road to self reliance and economic freedom. A human being is a holistic unit with the body, mind and soul. All these facets need to be in agreement if the lives of single mothers are to be enhanced especially with regard to poverty alleviation and surmounting the pressure thereof. No wonder, it is usually said that people perish for lack of knowledge, ignorance not simply because there is no help.

\subsection{Monitoring and evaluation of projects}

Zimbabwe has witnessed many NGOs and projects that emerge and just vanish like mist leaving the communities and people high and dry with no hope or help (Alao, 2012). This can be attributed to the lack of vision, planning, monitoring and valuation of such projects (Zastrow, 2010). The lack of accountable and corrupt people who are only interested in having the larger piece of the cake has led to the death of many developmental projects that could have brought a favourable turn around to single mothers in Zimbabwe and their children (Alao, 2012). Monitoring and evaluation allows progress to be assessed to foresee potential hazards that can compromise the fruitfulness of projects and their lifespan.

\subsection{Partnership between NGOs and the government}

Incontrovertibly, the political jigsaw of Zimbabwe between the Movement of Democratic Change (MDC) and Zanu PF has brought so much friction between NGOs and the government (Alao, 2012). The tension is so intense such that they are like two bulls in one kraal. As is always the case, it is the most vulnerable individuals, among them the single mothers together with their children who pay for the differences of these political establishments. The only way out for improved social services is for the government and the NGOs to join forces against poverty and other social ills (Ismael, 2006). This can be done by sharing resources, making cross referrals and educational workshops to ensure that they are both on the same level. Otherwise, much effort will be wasted in biting the air instead of tacking the real problems at hand.

\subsection{Participation at grassroots level}

People may be poor but their social importance is not determined by the degree to which they are prone or vulnerable to poverty, sickness and HIVIAIDS (Zastrow, 2010). The problem is best solved when the one wearing the shoes is asked where it pinches. In this way, the right way forward can be implemented (Chui and Wilson, 2006). Many governments including the government of Zimbabwe and NGOs have a tendency to prescribe solutions to the vulnerable as if poverty is a medical problem that can go away with an aspirin. Proper planning is only possible where there is community engagement and self- determination (Zastrow, 2010; Moyo, 2005). Such kind of partnership between the community and single mothers will give the single mothers a voice and a sense of belonging to the strategies that are aimed at relieving 
them from the pressure of poverty.

\section{Theoretical Frame}

\subsection{The Strength's Perspective Theory.}

This theory deviates from the medical line of work which emphasises on the deficiencies, pathologies of individuals in an attempt to provide a remedy for the problem at hand (Saleeby, 2005). As the name implies, the strength perspective seeks to recognize, build, utilize and reinforce the strengths and potentials that the individuals already possess, in this case single mothers (Zastraw, 2010). The pivotal principle beyond this theory is a firm belief in the ability of people to explore the resources available to them in order to satisfy their needs (Chapin, 2011). In a nutshell, every environment has latent resources that are useful to people if identified and developed.

This theory helps to explain the resilience within single mothers despite some of them being exposed to messy divorce, abuse, neglect and poverty. In this regard, Chui and Wilson, $(2006 ; 121)$ say that, "This approach seeks to understand how marginalised and oppressed people have survived in an oppressive catastrophic environment; such survival strategies are indicators of strengths." What is needed is one to be goal oriented and focused, to embrace a sense of commitment and drive to surmount the overwhelming challenges underpinning single motherhood. As for single mothers, the desire to see their children escaping from the chronic cycle of poverty is their dive and source of determination (Norman, 2012).

With proper and adequate support from the family, government and Non-Governmental Organizations (NGOs), single mother families are able to up their living standards and thereby alleviating poverty and other exertions. Where a person's mistakes or weaknesses are given the spot light, frustrations, helplessness and hopelessness, this is an opportunity to perpetuate sense of despondency, hopelessness, apathy and vicious poverty cycle (Chapin, 2011). The strength perspective on the other hand elicits a boost in self esteem, courage and hope which are needed for sustainable development of children as well as the lone mothers (Chui and Wilson, 2006; Zastraw, 2010; Norman, 2012). So, with the right attitude, single mothers can utilise the land, water, space and whatever the environment can offer to hammer down their worst enemy called poverty.

\section{Conclusion}

Although the lives of single mothers in Zimbabwe has been exacerbated by political, policy and societal structures such as patriarchy, they need to be encouraged to unleash their potent, potential, intuition and initiative in order to turn around their vulnerable social and economic position. The government should consider applying affirmative action to selectively help this group of its citizens to trounce poverty and therefore break its vicious cycle. This is even more compelling in the current dispensation of HIVIAIDS in which this group appears to be targeted by HIVIAIDS. This state of feminization of HIVIAIDS needs to be tackled from all fronts through education and interventions that will economically turn around the situation of single mothers. These researchers would like to use this platform to call upon the government of Zimbabwe to relax their political stance to give a palatable environment for the women friendly NGOs to take root in Zimbabwe. A conducive collaboration between the government and these bodies can bear great dividend that can possibly bring light and empowerment of single mothers in Zimbabwe. This will also be tantamount to achieving the much desired MDG number three that envisages seeing gender equality and equity as well as women empowerment and development take strong grounds in Zimbabwe.

\section{References}

Alao, A.( 2012). Mugabe and the Politics of Security in Zimbabwe. Canada: McGill-Queen's University.

Bose, C.E. (2010). Women in 1900: Gateway to the Political Economy of the 20th Century. Temple University Press: Philadelphia.

Byamugisha, G., Steinitz, L.Y., Williams, G. \& Zondi, P. (2002). Journeys of Faith. Church based responses to HIV and AIDS on three Southern African countries. G \& A Williams, Oxford, U.K.

Chant, S. (2006). Re-thinking the "Feminization of Poverty" in Relation to Aggregate Gender Indices. Journal of Human Development. Vol \&, No. 2.

Chapin, R. (2011). Social Policy for Effective Practice: A strengths Approach. Routledge: New York.

Chikuhwa, J.W. (2008). Zimbabwe: Beyond School Certificate. AuthorHouse: Bloomington.

Chui, W.H. \& Wilson, J. (2006). Social Work and Human Services best Practice. The Federation Press: New York.

Corcoran-Nantes, Y. (2005). Lost Voices: Central Asian Women Confronting Transition. Zed Books: New York. 
Courture, P. (2007). Child Poverty: Love Justice and Social Responsibility. Chalice Press: Danvers.

Delchambre, P. (2010). Zimbabwe: A Passion Shared. Boekenplan: Maastricht.

Ditmore, M.H. (2011). Historical Guide to Controversial Issues In America: Prostitution and Sex Work. Greenwood: California.

Dlamini, N. (2006). Measurement and Characteristics of Single Mother in South Africa: An Analysis Using 2002 General Household Survey. Unpublished Thesis, University of Kwazulu-Natal, South Africa. Pages 1-154.

Economi Report on Africa (2005). Meeting the Challenges of Unemployment and Poverty in Africa: Addis Ababa.

Elam, A.B. (2008). Gender and Entrepreneurship: A Multi-level Analysis. Edward Elgar Publishing Ltd: Cheltenham.

Exil, M. F. (2005). Women Freedom is Yours In Christ Jesus. Xulon Press: New York.

Frances, R. (2007). Selling Sex: A Hidden History of Prostitution._UNSW Press: Sydney.

Gebre-Egziabher, T.( 2010). Livelihood and Urban Poverty Reduction in Ethiopia: Perspective from small and big towns. OSSREA Press: Addis Ababa.

Gilbert, G. (2004). World Poverty: A Reference Handbook. Library of Congress: California.

Hamann, K., Koslowski, P. \& Luetge, C. (2007). Globalization and Business Ethics. Ashgate: Hampshire.

Hayward, S. (2010). French Costume Drama of the 1950s: Fashioning Politics in Film. University of Chicago Press: Chicago.

Hein, C. (2005). Reconciling Work and Family Ideas: Practical Ideas from Global Experience. Universal Copy Right Convention: Danvers Ismael, S. (2006). Child Poverty and the Canadian Welfare State. The University of Alberta Press: Edmonton.

Johnson, A. (2009). Our Voices: Issues Facing Black Women in America. Universal Press: New York.

Kanchense, J. (2008). Zimbabwe's Child Brides: Using participatory Action to unleash Human Potential. Victoria: Trafford.

Kang'ethe, S.M. (2014a). Panacea and perfidy of Globalization as an

engine of social development in developing countries. Accepted for publication in the Journal of Human Ecology, India.

Kang'ethe S.M 2014b The panacea and perfidy of culture as a platform of behavior change with examples from Botswana and South Africa. In the press of Social Work Practitioner, University of Johannesburg, South Africa.

Kang'ethe SM \& Rhakudu M 2010. Religious Education book for form 2. Gaborone. Heinemann Publishers.

Kang'ethe SM 2012. Attitudes of PLWA and other selected communities in Tsabong towards operationalizing bio-medical and traditional therapies in tandem to face the AIDs epidemic. Social Work/Maatskaplike, 2012.46 (1). PP 55-69.

Kang'ethe SM 2013. Feminization of Poverty in Palliative Care Giving of People Living with HIV and AIDS and Other Debilitating Diseases in Botswana. Journal of Virology \& Microbiology http://www.ibimapublishing.com/journals/JVM/jvm.html Vol. 2013 (2013), Article ID 772210, 7 pages. DOI: 10.5171/2013.772210.

Kilbride PL \& Rage DR 2012. Rural Marriage for our Times: A Reinvented Option? Praeger: California.

Landau J \& Griffith SJ 2007. The South African Family in Transition. Training and Therapeutic Implications Journal of Marital and Family Therapy. 7 (3), 339-344.r

Mahati ST, Chandiwana B, Munyati S, Chitiyo G, Mashange W, Chibatamoto P \& Mupambireyi, PF 2006). Our Children Our Future: From Vision to Inovative Impact Community Responses to Orphans and Vulnerable Children. A Qualitative assess of orphans and OVCs in two Zimbabwe Districts. HSRC Press: Cape Town.

Makina D \& Kanyenze G 2010. The Potential Contribution of the Zimbabwe Diaspora to the Economy's Recovery. Harare: UNDP.

Malaba J 2006. Poverty Measurement and Gender: Zimbabwe's Expeience. Inter-Agency and Expert Group Meeting on the Development of Gender Statistics. United Nations. New York. ESA/STAT/AC.122/14.2.

Morrissette M 2008. Choosing Single Motherhood: The Thinking Women's Guide. Wadsworth: Belmont.

Moyo S 2005. Land Policy, Poverty Reduction and Public Action in Zimbabwe. New York. ISS/UNDP Poverty and Public Action Paper No. 11.

Neckerman KM 2004. Social Inequality. Russell Sage Foundation: New York.

Norman E 2012. Resiliency Enhancement: Putting the strength perspective in to Social Work Practice. Columbia University: Columbia.

Peck JE 2004. Community Adaptations In Achieving Sustainable Livelihoods in Zimbabwe. University of Wisconsin: Madison.

Pelaez CM \& Paleaz CA 2007. Global Recession Risk: Dollar devaluation and the World Economy. New York.

Sachikonye L 2011. Zimbabwe's Lost Decade: Politics, Development and Society. Harare: Weaver Press.

Saleebey D (Ed.) 2005. The strengths perspective in social work practice (4th ed.). New York: Longman.

The World Bank 2003. Caribbean Youth Development: Issues and Policy Directions. Washington DC. UNDP. $2004 . \quad B o t s w a n a$ Millennium Development Goals Status Report 2004. Achievements, University.

Yarber AD \& Sharp PM 2010. Focus on the Single Parents families: Past Present and Future. Greenwood: California.

Zastraw C 2010. The Practise of Social Work: A comprehensive Worktext. 9th edition. Brooks/ Coles Press: Belmont.

Zastrow C 2009. Introduction to Social Work and Social Welfare: Empowering People. Brooks/ Coles: Belmont. 